\title{
Increase of sexually transmitted infections, but not HIV, among young homosexual men in Amsterdam: are STls still reliable markers for HIV transmission?
}

\author{
A K van der Bij, I G Stolte, R A Coutinho, N H T M Dukers
}

Sex Transm Infect 2005;81:34-37. doi: 10.1136/sti.2003.007997

Objectives: The incidence of HIV and STIs increased among men who have sex with men (MSM) visiting our STI clinic in Amsterdam. Interestingly, HIV increased mainly among older ( $\geqslant 35$ years) MSM, whereas infection rates of rectal gonorrhoea increased mainly in younger men. To explore this discrepancy we compared trends in STIs and HIV in a cohort of young HIV negative homosexual men from 1984 until 2002.

Methods: The study population included 863 men enrolled at $\leqslant 30$ years of age from 1984 onward in the Amsterdam Cohort Studies (ACS). They had attended at least one of the 6 monthly follow up ACS visits at which they completed a questionnaire (including self reported gonorrhoea and syphilis episodes) and were tested for syphilis and HIV. Yearly trends in HIV and STI incidence and risk factors were analysed using Poisson regression.

Results: Mean age at enrolment was 25 years. The median follow up time was 4 years. Until 1995 trends in HIV and STI incidence were concurrent, however since 1995 there was a significant $(p<0.05)$ increase in syphilis 10 to $1.4 / 100$ person years (PY)) and gonorrhoea incidence (1.1 to 6.0/ $100 \mathrm{PY}$ ), but no change in HIV incidence (1.1 and $1.3 / 100$ PY).

Conclusions: The incidence of syphilis and gonorrhoea has increased among young homosexual men since 1995, while HIV incidence has remained stable. Increasing STI incidence underscores the potential for HIV spread among young homosexual men. However, several years of increasing STIs without HIV, makes the relation between STI incidence and HIV transmission a subject for debate.

$\mathrm{R}$ isky sexual behaviour and incidence of sexually transmitted infections (STIs), including HIV, are increasing internationally among men who have sex with men (MSM). ${ }^{1-6}$ Accordingly, incidence of STIs has increased among MSM visiting our STI clinic in Amsterdam. ${ }^{17}$ HIV and syphilis incidence, however, has increased mainly among older ( $\geqslant 35$ years) MSM, whereas infection rates of rectal gonorrhoea have increased mainly in younger men. ${ }^{1}$

Since assessing the HIV incidence through longitudinal studies is costly and time consuming, other STIs have been used as markers to evaluate changes in HIV incidence and to asses effectiveness of intervention programmes. ${ }^{8}$ However, STI and HIV incidences do not necessarily have to coincide. We therefore studied data of the Amsterdam Cohort Study (ACS), which has followed a large group of HIV negative homosexual men over a long period, to assess the reliability of STIs as markers for HIV incidence.

\begin{abstract}
METHODS
Study population

The ACS among homosexual men started in 1984. Until 1995 HIV negative men of all age groups, who had at least two male sexual partners in the previous 6 months and lived in Amsterdam, Netherlands, were recruited. After June 1995 only men $\leqslant 30$ years were recruited and in February 1996 follow up of men $>35$ years was discontinued. Criteria for this ongoing study were at least one male sexual partner in the past year. Since 1984-95, recruitment has entailed "convenience sampling" (brochures at the STI clinic and gay entertainment places; advertisements), and "chain referral sampling" (participants recruited by other participants). Most participants defined themselves as exclusively homosexual. ${ }^{9}$ To evaluate incidence of HIV and STIs over time we included all HIV negative ACS participants $\leqslant 30$ years at entry. They were followed until aged 35 .
\end{abstract}

\section{Data collection}

Every 6 months ACS participants visited the municipal health service and completed a questionnaire, including self reported risk behaviour and episodes of gonorrhoea and syphilis. In addition, they were tested for HIV at every 6 monthly visit, and since 1995 also for syphilis. This enabled us to compare Treponema pallidum haemagglutination assay (TPHA) detected syphilis cases (that is, becoming reactive to the TPHA) with self reported syphilis from 1995-2002. As similar accuracy (nine versus eight cases) was found, we thus relied on self reported syphilis infections to evaluate incidence trends from 1984-2002. Hence, we defined a new case of gonorrhoea or syphilis as a self reported new episode in the past 6 months. HIV antibodies were detected using commercially available recombinant HIV-l/HIV-2 enzyme assays (mainly enzyme immunoassay (EIA); Abbott Laboratories, Abbott Park, IL, USA) and confirmed by western blot (mainly Diagnostics Biotechnology, Herent, Belgium). We estimated date of HIV seroconversion as the midpoint between the last HIV negative and the first HIV positive test. Two HIV seroconverters, with an interval between the last negative test and the first positive test of more than 2 years, were excluded from analysis. The median time between the last negative and first positive test was 175 days (interquartile range (IQR) 91-190 days) for included seroconverters.

To evaluate changes in risk behaviour over time we looked at differences in the number of lifetime partners reported at entry before and after 1995. In addition, changes in the number of partners and the percentage of participants

Abbreviations: EIA, enzyme immunoassay; GEE, generalised estimation equation; $P Y$, person years; IQR, interquartile range; $M S M$, men who have sex with men; RR, rate ratio; TPHA, Treponema pallidum haemagglutination assay 


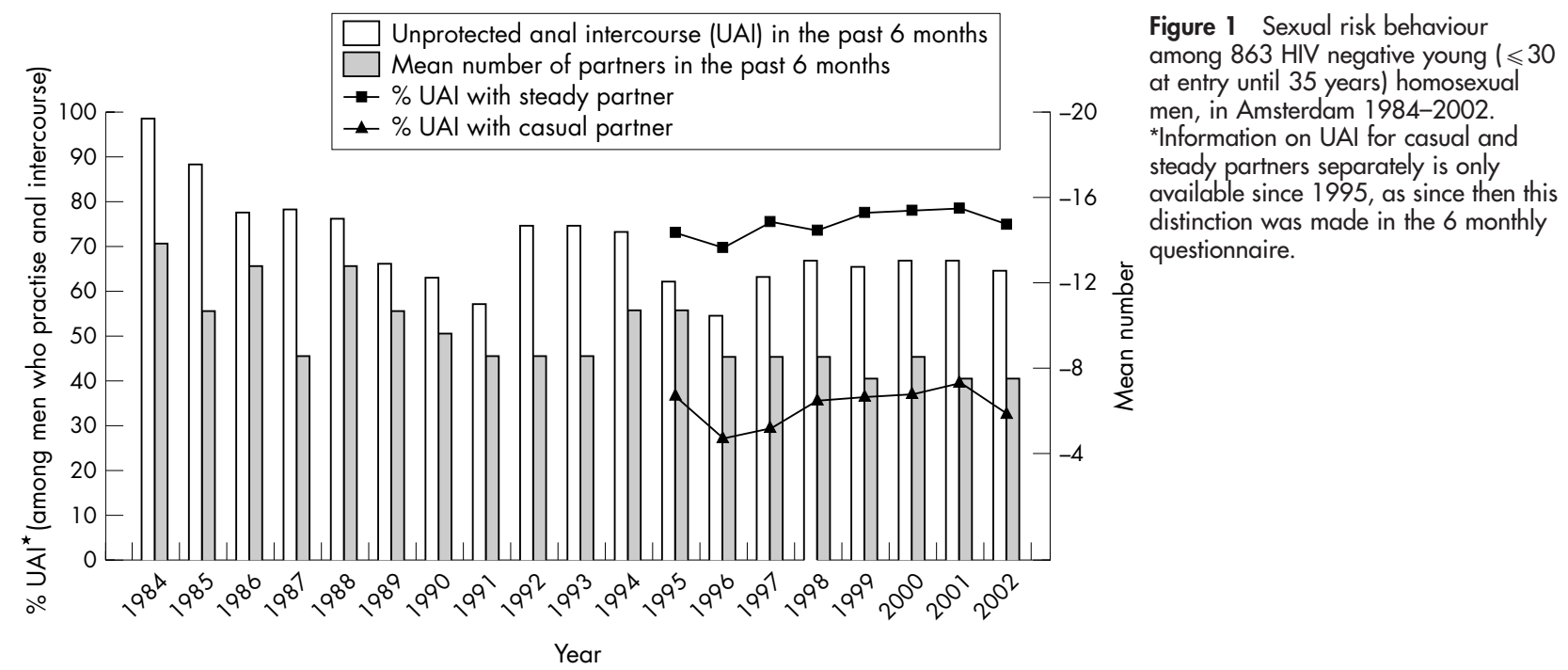

reporting unprotected anal intercourse in the past 6 months were evaluated from 1984-2002. Since 1995 a distinction between casual and steady partners was made in the 6 monthly questionnaires and therefore it was possible to evaluate changes in sexual risk behaviour for both casual and steady partners separately from 1995 onwards.

\section{Statistical methods}

We calculated incidence of STIs and HIV per annum as the number of new infections divided by total person years (PY) under observation. We analysed yearly incidence trends from 1984-2002 with year as a continuous variable and performed risk factor analysis for STIs and HIV infection on data since 1995 using Poisson regression. Risk factor analysis included the following variables: calendar time, country of birth, age (as a time dependent variable), education, money for sex, unprotected anal intercourse and unprotected oral sex with a steady partner in the preceding 6 months, unprotected anal intercourse and unprotected oral sex with a casual partner in the preceding 6 months, history of STI and concurrent STI. In addition, interaction terms between the sociodemographic variables (that is, country of birth, education, and age) and calendar time were performed. We performed multivariate analysis using backward selection to obtain a multivariate model containing statistically significant variables only. We tested differences between men enrolled since 1984 and men enrolled since 1995 using Wilcoxon and $\chi^{2}$ tests. Changes in sexual risk behaviour over time were analysed and the estimates and standard errors were corrected for intraindividual correlation between visits of the same person by using the generalised estimation equation (GEE), ${ }^{10}$ assuming an independent correlation matrix. Statistical significance was defined by $\mathrm{p}<0.05$.

\section{RESULTS}

Our sample included 863 HIV negative homosexual men $\leqslant 30$ years at entry with more than one ACS visit since 1984. Of these, 603 enrolled since 1995. Mean age at ASC entry was 25 years and $88 \%$ were of Dutch nationality. Median follow up time in the study was 4.0 years (IQR 1.5-6.6 years). A total of 9488 visits were made by the 863 men. The median duration between visits was 175 days (IQR 94-188 days). Men enrolled before and after 1995, did not differ with respect to nationality and education. However, men entering before 1995 were older (27 versus 25 years, $p<0.001$ ) and reported more lifetime sexual partners at entry (median number: 87 versus 20, $\mathrm{p}<0.001)$. In addition, men entering before 1995 reported more unprotected anal intercourse in the preceding 6 months at entry (fig 1).

Since 1984, 124 gonorrhoea, 18 syphilis, and 73 HIV infections were observed (92, eight, and 25 infections, respectively, since June 1995). Figure 2 shows incidences between 1984 and 2002. Incidence of HIV peaked in 1984-5 (6.7 per $100 \mathrm{PY}$ ) and decreased significantly to 1.3 per $100 \mathrm{PY}$ in 1988 (yearly rate ratio $(R R)$ : $0.65, p=0.02$ ). Similar patterns are observed for gonorrhoea and syphilis incidences (yearly RR: $0.54, \mathrm{p}=0.004$ and $0.69, \mathrm{p}=0.38$ respectively). Around 1990-1 a short term concurrent rise in both HIV and STI incidence was noticeable. However, since 1995, incidence of HIV has remained stable, being 1.1 per $100 \mathrm{PY}$ in 1995 and 1.3 per 100 PY in 2002 (yearly RR: 0.93, p=0.48), whereas gonorrhoea incidence has increased from 1.1 in 1995 to 6.0 in 2002 (yearly RR: 1.27, p<0.001). Since 2000, syphilis incidence has increased as well, from 0 per 100 PY in 1999 to 1.4 per $100 \mathrm{PY}$ in 2002 (yearly RR: 2.47, p=0.03). The increase in STIs was similar for all demographic subgroups.

In addition to an increasing STI incidence, sexual risk behaviour also showed an increase since 1995 when corrected for age; from 1995 to 2002 the percentage of men reporting unprotected anal intercourse increased significantly (OR $1.06, \mathrm{p}<0.01)$. When we evaluated unprotected anal intercourse for both casual and steady partners separately, we found this increase in risk behaviour to be more evident for unprotected anal intercourse with steady partners (OR: 1.07,

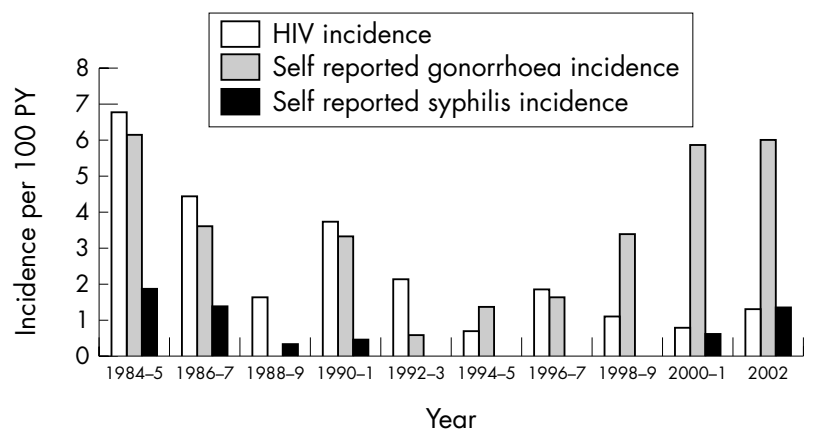

Figure 2 Incidence of gonorrhoea, syphilis and HIV per 100 PY among 863 HIV negative young ( $\leqslant 30$ at entry until 35 years) homosexual men, in Amsterdam 1984-2002. 


\begin{tabular}{|c|c|c|c|c|}
\hline \multirow[b]{2}{*}{ Factors } & \multirow[b]{2}{*}{ No (\%) } & \multirow{2}{*}{$\begin{array}{l}\begin{array}{l}\text { Gonorrhoea, self } \\
\text { reported }\end{array} \\
\text { RR }(95 \% \mathrm{Cl})\end{array}$} & \multirow{2}{*}{$\frac{\text { Syphilis }}{\text { RR (95\% CI) }}$} & \multirow{2}{*}{$\begin{array}{l}\text { HIV } \\
\text { RR }(95 \% \mathrm{Cl})\end{array}$} \\
\hline & & & & \\
\hline \multicolumn{2}{|l|}{ Calender time (per annum) } & $\begin{array}{l}1.27(1.1 \text { to } 1.4)^{\star} \\
1.20(1.1 \text { to } 1.3)^{*} \dagger\end{array}$ & $\begin{array}{l}2.13(1.2 \text { to } 3.7)^{\star} \\
2.17(1.2 \text { to } 3.8)^{*} \ddagger\end{array}$ & $0.93(0.8$ to 1.2$)$ \\
\hline $\begin{array}{l}\text { Country of birth (non-Dutch } \\
\text { versus Dutch) }\end{array}$ & $76(13 \%)$ & $1.0(0.5$ to 2.0$)$ & $3.1(0.6 \text { to } 15.3)^{+}$ & $1.8(0.6$ to 5.3$)$ \\
\hline Age $\geqslant 26$ versus $<26$ & $255(42 \%)$ & $0.8(0.5$ to 1.2$)$ & $0.5(0.1$ to 2.0$)$ & $2.2(0.8$ to 6.4$)$ \\
\hline $\begin{array}{l}\text { Education (at least college } \\
\text { degree versus other education) }\end{array}$ & $363(60 \%)$ & $0.9(0.6$ to 1.4$)$ & $0.5(0.1$ to 1.7$)$ & $\begin{array}{l}0.38(0.2 \text { to } 0.8)^{*} \\
0.37(0.2 \text { to } 0.9)^{\star} \S\end{array}$ \\
\hline Money for sex (yes versus no) & $52(8 \%)$ & $1.6(0.8$ to 3.0$)$ & $\begin{array}{l}6.5(1.6 \text { to } 26.0)^{*} \\
7.9(2.0 \text { to } 31.6)^{*} \ddagger\end{array}$ & $1.8(0.5$ to 5.9$)$ \\
\hline $\begin{array}{l}\text { Unprotected anal intercourse } \\
\text { with steady partner (yes versus } \\
\text { other) }\end{array}$ & $1563^{* *}(32 \%)$ & 1.5 (0.9 to 2.2$)$ & $1.6(0.4$ to 6.1$)$ & $0.8(0.3$ to 1.9$)$ \\
\hline $\begin{array}{l}\text { Unprotected anal intercourse } \\
\text { with casual partner } \\
\text { (yes versus other) }\end{array}$ & $638^{* *}(13 \%)$ & $\begin{array}{l}2.6(1.6 \text { to } 4.0)^{*} \\
1.9(1.2 \text { to } 2.9)^{*} \dagger\end{array}$ & $3.2(0.8$ to 12.8$)$ & $\begin{array}{l}2.5(1.1 \text { to } 6.1)^{\star} \\
2.7(1.1 \text { to } 6.5)^{\star} \S\end{array}$ \\
\hline $\begin{array}{l}\text { Unprotected oral sex with } \\
\text { steady partner (yes versus } \\
\text { other) }\end{array}$ & $\begin{array}{l}2305^{\star *} \\
(47.6 \%)\end{array}$ & $1.3(0.9$ to 1.9$)$ & $1.4(0.4$ to 5.1$)$ & $0.7(0.3$ to 1.6$)$ \\
\hline $\begin{array}{l}\text { Unprotected oral sex with } \\
\text { casual partner (yes versus } \\
\text { other) }\end{array}$ & $\begin{array}{l}1889^{* *} \\
(38.9 \%)\end{array}$ & $\begin{array}{l}3.2(2.0 \text { to } 4.9)^{*} \\
2.4(1.5 \text { to } 3.7)^{*}+\end{array}$ & $1.2(0.3$ to 3.6$)$ & $0.9(0.4$ to 2.0$)$ \\
\hline History of STI (yes versus no) & $81^{* *}(13 \%)$ & NA & NA & $0.6(0.2$ to 2.1$)$ \\
\hline $\begin{array}{l}\text { Concurrent STI with HIV } \\
\text { (yes versus no) }\end{array}$ & $2^{* *}(0.04 \%)$ & NA & NA & $3.5(0.8$ to 15.1$)$ \\
\hline \multicolumn{5}{|c|}{$\begin{array}{l}\text { *Significant at } p<0.05 \text {. } \\
\text { †Multivariate results, model containing calendar time, unprotected anal intercourse with casual partner, and } \\
\text { unprotected oral sex with casual partner. } \\
\text { †Multivariate results, model containing calendar time and money for sex. } \\
\text { \$Multivariate results, model containing education and unprotected anal intercourse with casual partner. } \\
\text { "Not applicable. } \\
\text { **Number of visits were reported. }\end{array}$} \\
\hline
\end{tabular}

$\mathrm{p}<0.01$ ) than with casual partners (OR:1.04, $\mathrm{p}=0.11$ ) (fig l). The number of sexual partners (total and casual partners) per 6 month period, however, did not change significantly $(p=0.5)$, being 11 and 10 respectively in 1995 versus eight and eight respectively in 2002 .

We performed further analysis on men included after 1995 to see whether risk factors differed among HIV, gonorrhoea, and syphilis, in ways that could explain discordant incidences. Multivariate results showed that men who reported unprotected anal intercourse with casual partners were more likely to become infected with gonorrhoea or HIV (table 1). For gonorrhoea, but not for HIV, men who reported unprotected oral sex with casual partners were also at higher risk to become infected. Concurrent STI infection (syphilis and gonorrhoea) was borderline significant for HIV infection $(\mathrm{p}=0.085)$.

\section{DISCUSSION}

In our study population, STI incidence increased since 1995 whereas HIV incidence did not. STIs are often considered markers for high risk sexual behaviour and HIV transmission, and are an important cofactor for the transmission and acquisition of HIV infection. ${ }^{11}$ However, what could explain this unchanged HIV incidence?

The number of HIV seroconversions since 1995 was small, which makes the evidence for the direction of HIV incidence trend statistically weak. However, these small numbers were sustained over time, pointing to low risk. Furthermore, men enrolled since 1995 reported less risk behaviour and could be viewed as low risk for HIV infection compared to men enrolled in 1984-94.

Secondly, HIV transmission may lag behind the transmission of other STIs because of lower infectivity. ${ }^{12}$ Moreover, availability of HAART has reduced HIV loads, making HAART treated individuals even less infectious.

In addition, both syphilis and gonorrhoea can be transmitted orally as well as anally, ${ }^{13}$ whereas oral transmission of HIV is less common. ${ }^{14}$ In our study, unprotected anal intercourse with casual partners was an independent risk factor for both HIV and gonorrhoea, whereas unprotected oral sex was an independent risk factor only for gonorrhoea. Increase in gonorrhoea may in part reflect a rise in oral sex in STI risk groups seeking to reduce the HIV risk of anal sex.

The finding that HIV incidence remained stable among younger homosexual men in Amsterdam, but seems to increase among older men, ${ }^{7}$ suggests different sexual networks for younger men that are relatively HIV free but not STI free. In addition, the stable incidence of HIV might also point to men having intercourse preferably with men of concordant serostatus. If this is the case spread of HIV is likely to increase with more mixing between age groups and people of discordant serostatus.

However, some limitations with respect to the generalisation of our findings should be noted. First of all, our sample can be considered strongly homosexually identified ${ }^{9}$ and might not be representative of the broader population of men who have sex with men. In addition, our sample was a convenience sample based in the Amsterdam metropolitan area and was intermediate or highly educated. Caution is therefore required when results are generalised to other settings.

Finally, increasing STI incidence, and a simultaneous increase in sexual risk behaviour, underscores the potential for HIV spread among young homosexual men. However, our findings make the relation between STI incidence and HIV transmission a subject for debate. 


\section{Key messages}

- Increase in risk behaviour, gonorrhoea, and syphilis, but not HIV, among young homosexual men

- Possible explanations for discordance in STI and HIV incidence: availability of HAART, shifts in sexual risk behaviour, and differences in infectivity, transmission routes, and sexual networks

- STI incidence as markers for HIV transmission ought to be a subject for debate

\section{ACKNOWLEDGEMENTS}

The authors thank U Davidovich, H Fennema, R Geskus, and A van den Hoek for critically reading and commenting on the manuscript; $\mathrm{H}$ van Bijnen, D Mulder, and D Ram for data collection; and L Phillips for editing the final manuscript. We furthermore wish to thank all study participants.

\section{CONTRIBUTORS}

AvdB analysed and interpreted the data and drafted the manuscript; IS contributed to the acquisition and interpretation of data and commented on the manuscript; RC contributed to the interpretation of data and helped in drafting the manuscript; ND supervised the study, contributed to the interpretation of data, and commented on the manuscript.

\section{Authors' affiliations}

A K van der Bii, I G Stolte, R A Coutinho, N H T M Dukers, Department of HIV and STD Research, Municipal Health Service of Amsterdam, Amsterdam, Netherlands

R A Coutinho, Department of Human Retrovirology, Academic Medical Center, University of Amsterdam, Amsterdam, Netherlands

This study was performed as part of the Amsterdam Cohort Studies on AIDS, a collaboration between the Municipal Health Service, the Academic Medical Center, and CLB/Sanquin, Amsterdam, Netherlands and is sponsored by the Netherlands Organisation for Health Research and Development, the Ministery of Health, Welfare and Sport, and the AIDS Fonds.
The authors report no conflict of interest.

Correspondence to: Akke van der Bii, Department of HIV and STD Research, Municipal Health Service Amsterdam, PO Box 2200, 1000 CE Amsterdam, Netherlands; Avdbij@gggd.amsterdam.nl

Accepted for publication 14 April 2004

\section{REFERENCES}

1 Fennema JS, Cairo I, Spaargaren J, et al. Syphilis epidemic and an increase of the number of HIV infections among homosexual men attending the Amsterdam venereal disease clinic. [In Dutch] Ned Tijdschr Geneeskd 2002; 146:633-5.

2 del Romero J, Castilla J, Garcia S, et al. Time trend in incidence of HIV seroconversion among homosexual men repeatedly tested in Madrid, 19882000. AIDS 2001;15:1319-21.

3 Hogg RS, Weber AE, Chan K, et al. Increasing incidence of HIV infections among young gay and bisexual men in Vancouver. AIDS 2001;15:1321-2.

4 Centers for Disease Control and Prevention. Primary and secondary syphilis among men who have sex with men-New York City, 2001. MMWR 2002:51:853-6.

5 Dodds JP, Nardone A, Mercey DE, et al. Increase in high risk sexual behaviour among homosexual men, London 1996-1998: cross sectional questionnaire study. BMJ 2000;320:1510-1.

6 Spenatto N, Viraben R. Substantial increase in gonorrhoea among homosexual men attending an STD centre in Toulouse, France. Sex Transm Infect $2001 ; 77: 391-2$.

7 Dukers NH, Spaargaren J, Geskus RB, et al. HIV incidence on the increase among homosexual men attending an Amsterdam sexually transmitted disease clinic: using a novel approach for detecting recent infections. AIDS 2002; 16:F19-F24.

8 National Institutes of Health. Consensus statement online. Interventions to prevent HIV risk behaviors 1997;15-2:1-41 (11-13 February).

9 Davidovich U, de Wit JB, Stroebe W. Assessing sexual risk behaviour of young gay men in primary relationships: the incorporation of negotiated safety and negotiated safety compliance. AIDS 2000;14:701-6.

10 SAS Institute I. SAS/STAT Software: changes enhancements through release 6.12. SAS Institute, 1996.

11 Cohen MS. Sexually transmitted diseases enhance HIV transmission: no longer a hypothesis. Lancet 1998;351(Suppl 3):5-7.

12 Wasserheit JN, Aral SO. The dynamic topology of sexually transmitted disease epidemics: implications for prevention strategies. $J$ Infect Dis 1996;174(Suppl 2):S201-S213.

13 Edwards S, Carne C. Oral sex and the transmission of non-viral STIs. Sex Transm Infect 2003;74:95-100.

14 Page-Shafer K, Shiboski CH, Osmond DH, et al. Risk of HIV infection attributable to oral sex among men who have sex with men in the population of the men who have sex with men. AIDS 2003;16:2350-2. 